\title{
The impact of coaching on the emotional and social intelligence competencies of leaders
}

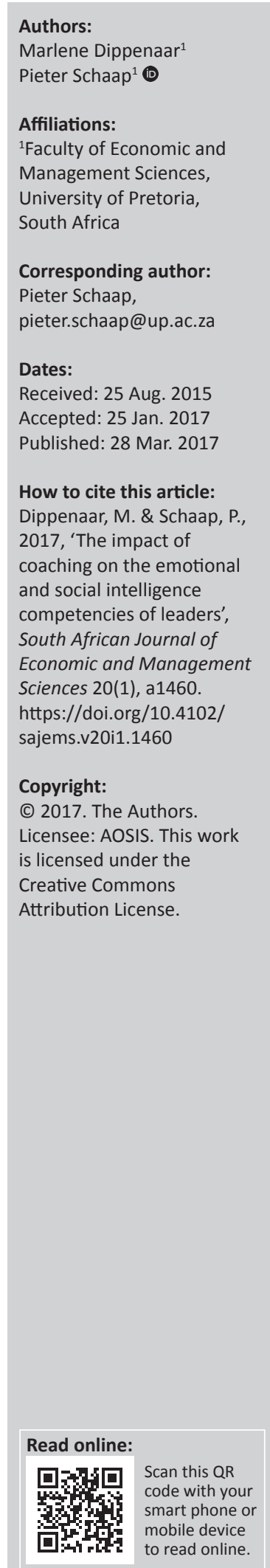

Background: The development of the emotional intelligence of leaders has become an exceptionally popular enterprise. However, the empirical research conducted by practitioners to date does not provide convincing evidence of the effectiveness of emotional intelligence development interventions. Robust and informative research on the effectiveness of coaching to develop the emotional intelligence of leaders is lacking.

Aim: The purpose of this study was to determine, describe and evaluate the impact of a theoretically substantiated coaching intervention on the emotional and social intelligence competencies of leaders in a financial services company.

Setting: The setting of the study is a financial services company in South Africa.

Methods: A mixed method approach using a quantitative and qualitative research design was considered appropriate. The quantitative research method consisted of a quasi-experimental design using a non-equivalent pre- and post test control group to measure the impact of the coaching intervention on a sample of 30 leaders. The Bar-On EQ-i scale was selected as a reliable and valid measure of emotional and social intelligence competencies. Wilcoxon's statistic was calculated to determine the statistical significance of score differences between the experimental $(N=30)$ and control $(N=30)$ groups. The qualitative research method was comprised of semi-structured interviews with six of the leaders and their supervisors.

Results: The statistical results indicated that coaching significantly impacted the emotional and social intelligence competencies of leaders in terms of their overall emotional quotient (EQ), intrapersonal competency, interpersonal skills, stress management, self-regard and empathy. The semi-structured interviews provided rich descriptive themes and evaluations that corroborated the quantitative findings.

Conclusion: This research provided convincing empirical evidence of the positive impact of a long-term, spaced and goal-focused coaching intervention on the emotional and social intelligence competencies of leaders in a financial services institution. The finding suggests that a theoretically well substantiated coaching intervention and a robust empirical study can be effective in demonstrating the impact of coaching on the emotional and social intelligence competencies of leaders. However, the implications of the limitations pointed out in this study could have influenced the findings, and future research aimed at improving relevant research models should take these into account.

\section{Introduction}

Most organisations constantly search for ways to improve the capabilities of their leaders so as to keep pace with the ever-changing business environment. Leaders often lack effective leadership behaviour; therefore, they need effective interventions to develop their emotional and social intelligence competencies. The relevance of emotional intelligence (EI), also often referred to as 'emotional and social intelligence', to effective leadership behaviour in organisations is supported by numerous studies (Kotzé \& Venter 2011; Prins, Van Niekerk \& Weyers 2011; Van Oosten 2013).

Whereas the concept of emotionally intelligent behaviour is continually being developed and clarified as far as it is applicable at a personal level, there is a distinctive need to extend existing research to examine the development of emotionally intelligent behaviour in a work setting (Goleman 1998). Groves, McEnrue and Shen (2008) note that, although the discipline of EI training has become an exceptionally popular industry, the experimental evidence provided thus far creates reservations about how effective the purposeful development of leaders' EI really is. According to Groves et al. (2008), there seem to be limited publications on EI training studies that are well-designed and psychometrically rigorous. In their comprehensive review across multiple 
academic and professional fields, McEnrue, Groves and Shen (2010) confirm that there are a number of training suppliers in the field of emotional training but that empirical evidence substantiating the quality and effectiveness of their training is lacking.

According to Boyatzis et al. (2013), typical leadership training has only a minor effect on permanently transforming leaders' emotional and social intelligence behaviour, for instance, their emotional self-awareness, emotional selfcontrol, optimism and adaptability. The problem with typical leadership training seems to revolve around the lack of transfer of training, which characterises traditional training approaches that emphasise teacher-learner, short-term, massed and one-size-fits-all classroom-based training (Grant 2007; McEnrue et al. 2010). On the other hand, theoretically justified coaching programmes emphasising a holistic, multilevel, staged and intentional change process appear to have more lasting effects. More specifically, integrated and holistic coaching models implemented over the longer term and comprising frequent and goal-specific interventions appropriately spaced within a given time frame have proved to be more effective in transforming leaders' behaviour permanently (Grant 2007, 2010; Grant, Curtayne \& Burton 2009; Passmore 2010).

This study aimed to rigorously and empirically investigate the effectiveness of a coaching intervention in developing the emotional and social intelligence competencies of leaders. It was posited that emotional and social intelligence competencies as presented in the Bar-On model could be developed by using an appropriately designed and theoretically substantiated coaching approach (Bar-On 1997).

More specifically, the researchers set out to determine, describe and evaluate the impact of a holistic, longer-term, spaced and goal-focused coaching intervention on the emotional and social intelligence competencies of leaders in a financial services company in South Africa.

It was hoped that the research would be of value to academic research, the profession of executive coaching, the practice of leadership development, and organisations in general. The study aimed to address the conceptual and assessment shortcomings of current studies on the process of EI development and to expand and enhance research and theory concerning the development of leaders' emotional and social intelligence competencies that are required for effective leadership.

The remainder of this article is structured as follows: The 'Literature review' section provides a literature review seeking conceptual clarification of EI, emotional and social intelligence competencies, effective leadership and executive coaching. The efficacy of executive coaching and EI development programmes is reviewed, and a holistic executive coaching model is proposed and described. The 'Research design' section provides the research approach, the coaching intervention, the quantitative and qualitative research design.
The 'Discussion' section provides the quantitative and qualitative findings, synthesis, an explanation of the contribution and limitations of the study, recommendations for future research and conclusive remarks.

\section{Literature review}

\section{The emergence of emotional intelligence}

EI theories can be traced back to Edward Thorndike (1920) who first recognised the concept of social intelligence, which, in today's terms, is better known as EI (Hayward 2005). The term 'emotional intelligence' was coined by Peter Salovey and John Mayer in 1990 (Mayer, Roberts \& Barsade 2008). Mayer et al. (2008) argue that the four components in their model of EI, namely, the abilities to perceive emotions, use emotions to facilitate thought, understand emotions and manage emotions, combine to form a legitimate intelligence that is founded on the theory and definition of intelligence. Goleman (1995), who popularised the concept of EI, describes five skills that are related to EI: self-motivation, self-regulation, self-awareness, social skills (relationship management) and social awareness (empathy) (Hayward 2005). The Bar-On (1997) model of EI has been referred to as the most widely used model in the world (Prins et al. 2011). Bar-On (2006) describes this EI model as:

a cross-section of interrelated emotional and social competencies, skills and facilitators that determine how effectively we understand and express ourselves, understand others and relate with them, and cope with daily demands. (p. 2)

Over the past two decades, there has been much controversy and confusion about the concept of EI and about the theoretical soundness and acceptability of its definitions, models and measures.

\section{Distinguishing between emotional intelligence models}

Numerous models and measures of EI exist. Daus and Ashkanasy (2005) suggest that EI models and measures should be classified according to the research themes of ability, trait and mixed models. The model of Mayer, Salovey and Caruso (2000) differentiates EI as a distinct human ability, whereas mixed models focus on human effectiveness in broader terms. The models of Goleman (1995) and Bar-On (1997) can be described as mixed models because of the explicit inclusion of non-ability attributes or traits such as self-motivation, mood, self-regard and personal independence (Cherniss 2010). According to Cherniss, the lack of overlap between the different models has been a contentious issue among critics and supporters of EI. However, this author concludes that arguing whether certain models are more legitimate than others appears to be fruitless as all the major models are not only legitimate but also potentially useful depending on the outcome considered important (Cherniss 2010:123).

Therefore, for the purpose of this research, the focus is on the theoretical model and measure most suitable for the context of use and relevant outcomes under investigation. In this study, the emphasis falls on the coaching of emotional 
and social intelligence competencies relevant to effective leadership, which calls for a concept of EI that is broader than the narrowly defined one in the ability model of Salovey and Mayer (1990). According to McCleskey (2014) and Cherniss (2010), mixed models of EI can be considered emotional and social intelligence competency (ESC) models as these models involve competencies that go beyond emotional abilities to include traits and personal qualities. A competency can be considered an underlying characteristic of a person that may lead to superior performance (Boyatzis 2009). As such, emotional and social intelligence competencies (ESCs) can be conceptualised as behavioural manifestations of EI that may lead to outstanding work performance (Boyatzis 2009). Empirical support for a strong relationship between ESCs and performance at work is supplied in a systematic meta-analytic study by Joseph and Newman (2010). For the purposes of this study, the terms EI and ESC were used interchangeably depending on the term used by the specific author(s) being cited.

\section{The Bar-On model of emotional intelligence}

The Bar-On mixed model of EI was the model of choice for the purposes of this study as it is based on an ESC model (Daus \& Ashkanasy 2005). The relevance of the Bar-On model to the development of effective leadership behaviour in organisations is supported by a significant number of studies (Kotzé \& Venter 2011; Prins et al. 2011; Stein et al. 2009). The five main components and 15 sub-components of this model are described in more detail in Table 1 . The model represents a 1-5-15 hierarchical model with components that converge into a single component known as the emotional quotient (EQ). The first important main component, namely, intrapersonal competency, refers to the competency to be aware of oneself, to understand one's strengths and weaknesses and to be able to express thought and feelings in a constructive manner. Factors that facilitate or drive intrapersonal skills include self-reliance (independence) and self-actualisation in terms of achieving one's goals and potential. The second main component, namely, interpersonal skills, refers to the competency to be aware of other people's emotions, feelings and needs and to the ability to develop and maintain a cooperative, constructive and mutually satisfying relationship with others. The third main component, namely, stress management, refers to the ability to effectively and constructively manage the emotions a situation demands. Adaptability is the fourth main component and entails being in touch with external realities, adapting and adjusting to new situations and effectively solving problems of an interpersonal and intrapersonal nature. The fifth main component, namely, general mood, refers to an ability that serves to facilitate emotional and social intelligence behaviour and consists of self-motivating tendencies such as having an optimistic outlook on life and feeling content and happy with oneself.

\section{The link between emotional and social intelligence competencies and effective leadership}

According to Boyatzis (2009), ESC are predictors of effectiveness in professional, management and leadership roles and can be developed in adults. Van Oosten (2013) refers to a large number of empirical studies that support the relationship between ESCs and leadership behaviour or styles that are associated with effective leadership. Effective leadership may encompass performance with respect to both task outcomes and relationship outcomes. Task-related outcomes have to do with goal attainment and performance whereas relationship-related outcomes emphasise socialeconomic outcomes such as engagement, motivation, commitment and satisfaction. Several studies using different measuring instruments and statistical methods point to a positive link between EI and transformational and authentic leadership (Harms \& Credé 2010; Pillay, Viviers \& Mayer 2013; Syndell 2008). In a meta-analysis studying the link between EI and leadership, Harms and Credé (2010) found that the Bar-On mixed model of EI as measured by the Emotional Quotient Inventory (EQ-i) was a strong predictor of transformational leadership. More specifically, previous research has indicated connections between high EQ-i scores and effective leadership (Butler \& Chinowsky 2006).

The importance of developing leaders' ESCs to ensure effective leadership and organisational success is clear from

TABLE 1: Bar-On's emotional intelligence model.

\begin{tabular}{lll}
\hline Main component & Sub-component & Competency \\
\hline Intrapersonal & - Self-regard & - To accurately perceive, understand and accept oneself. \\
& - Emotional self-awareness & - To be aware of and understand one's own emotions. \\
& - Independence & - To effectively and constructively express one's emotions and oneself. \\
& - Self-actualisation & - To be self-reliant and free of emotional dependency on others. \\
- Empathy & - To strive to achieve personal goals and actualise one's potential. \\
- Social responsibility & - To be aware of and understand how others feel. \\
Stress management & - Interpersonal relationship & - To identify with one's social group and cooperate with others. \\
Adaptability & - Impulse control & - To establish mutually satisfying relationships and relate well with others. \\
& - Feality testing & - To effectively and constructively manage emotions. \\
- Problity & - To effectively and constructively control emotions. \\
& - Optimism & - To objectively validate one's feelings and thinking with external reality. \\
& - Happiness & - To adapt and adjust one's feelings and thinking to new situations. \\
\hline
\end{tabular}

Source: Adapted from Bar-On, R., 2006, 'The Bar-On model of emotional-social intelligence (ESI)', Psicothema 18(Suppl. 1), 13-25 
the existing research presented earlier in this article. However, numerous reviews have shown that leadership development programmes that follow a traditional teacher-learner or classroom-based training approach rarely show sustainable change in ESCs, and coaching has been suggested as an alternative approach (Boyatzis et al. 2013; Grant 2007; McEnrue et al. 2010). Coaching can help leaders understand their own emotional behaviour and make them mindful of the impact of their leadership style on their followers.

\section{The efficacy of executive coaching in leadership development}

The purpose of coaching in organisations is largely to develop leaders, and this is referred to as executive coaching. The practice of executive coaching has become progressively more popular in the business domain over the past decades and is seen as a fundamental developmental intervention by means of which organisations build executives' skills (Bono et al. 2009). Determining the efficacy or benefit of coaching in respect of leadership development requires an understanding of what executive coaching entails.

\section{Grant (2014) defines executive coaching as:}

a helping relationship formed between a client (the coachee) who has leadership, managerial, or supervisory authority and responsibility in an organisation, and a coach who uses a range of cognitive and behavioural techniques in order to help the client achieve a mutually defined set of goals with the aim of improving his or her leadership skills, professional performance, and well-being and the effectiveness of the organisation. (p. 2)

Although coaching may be defined specifically to suit an intended purpose and context, Passmore and Fillery-Travis (2011) came up with the following broad definition after studying research and publications spanning more than a decade: Coaching is:

a Socratic based future focused dialogue between a facilitator (coach) and a participant (coachee/client), where the facilitator uses open questions, active listening, summarises [sic] and reflections which are aimed at stimulating the self-awareness and personal responsibility of the participant. (p. 6)

According to these authors, the Socratic dialogue refers to guided discovery, where the coach believes that the answer to a question is located within the coachee. Thus, the coach's role is not that of an educator or trainer in the directive sense but that of a facilitator to self-discovery through shaping questions and focusing the attention on the next step of the process.

Unlike mentoring, training or consulting, coaching does not require in-depth domain-specific knowledge. However, effective coaches must have knowledge and experience of the psychology of stimulating self-awareness and personal responsibility that foster ongoing self-directed learning and personal growth. Bresser and Wilson (2010:9) state, 'At the heart of coaching lies the idea of empowering people by facilitating self-directed learning, personal growth and improved performance'. Executive coaching suggests an ongoing confidential partnership between coach and coachee (lasting a few months to a year and more), which is normally sponsored by a third party (the organisation) (Bozer \& Sarros 2012). According to Bartlett, Boylan and Hale (2014), the essence of coaching may be summarised by four keywords that are used in executive coaching definitions of 533 publications, namely, relationship, goals, learning and performance.

Much current literature on coaching explores executive coaching as a relatively new and promising practice linked to growth and development, but empirical research assessing the effects of coaching lags far behind the practice of coaching (Bono et al. 2009; Grant 2013). De Meuse, Dai and Lee (2009) emphasise that the effectiveness of executive coaching needs to be clearly and scientifically demonstrated. According to Page and De Haan (2014), studies on the effectiveness of executive coaching lack experimental designs that include objective quantitative measures and comparable control groups.

Recent meta-analytical studies by Theeboom, Beersma and Van Vianen (2014) and Jones, Woods and Guillaume (2016) show promising findings suggesting that coaching has significantly positive effects on various outcomes on different levels, for example, on organisational, affective, skills-based and individual (achievement, performance) levels. These meta-analysis studies indicate that coaching can be an effective intervention in organisations. However, each study pointed out the lack of robust research showing the fundamental mechanisms that make coaching interventions effective. Jones et al. (2016) and Theeboom et al. (2014) report that available research in the field of coaching provides insufficient details about specific coaching models, coaching schedules, coach and coachee characteristics, and tools and techniques used to allow for adequate theory building relating to the effectiveness of the different coaching processes and models. However, Jones et al. (2016) are of the opinion that research in educational psychology and theories on adult learning may provide relevant guidelines for effective coaching as coaching is, in effect, a high-fidelity form of training and development. Hence, the need for theoretically substantiated coaching interventions and sound empirical research to demonstrate the effectiveness of coaching is clear.

\section{The efficacy of emotional intelligence development programmes}

Despite the increasing popularity of coaching, evidence outlining the necessity of coaching to enhance leaders' EI and the impact of coaching is inadequate (Carey, Philippon \& Cummings 2011; Groves et al. 2008; McEnrue et al. 2010). A review by McEnrue et al. (2010:3-19) shows that existing research fails to adequately confirm whether it is viable to develop individuals' EI or in fact how to develop it. It seems that very few well-designed EI development studies that include valid measures of EI have been published (Groves et al. 2008). More recently, Schutte, Malouff and Thorsteinsson (2013) did a meta-analysis on EI training and highlighted only three experimental and control group design studies that had been done in an organisational context. 
These studies did show that EI training could have a significantly positive effect on EI. However, experimental and control group studies focusing specifically on the effect of coaching on EI in organisational contexts could not be found. Groves et al. (2008:226-231) highlight the following common problems with studies on EI training that inhibit the quality of research findings, problems which may equally apply to studies involving specific coaching (i.e. nondirective, high-fidelity training):

- EI conceptual and assessment concerns: Unknown or conceptually suspect EI models with questionable psychometric measurement qualities that make pre- and post-training results hard to interpret; no controlling mechanism to identify the presence of social desirability or other forms of personal biases that may have had an influence on reported development improvements.

- A lack of information concerning the training intervention: Lack of details about the duration, content, process and techniques applied to develop EI.

- Short duration of the training intervention: Irregular interventions of short duration that may not be as effective for developing EI as regular interventions extending over longer periods.

- Absence of essential statistical controls and/or a control group: Failure to control for demographic factors such as gender, age and work experience may account for the results obtained. A comparative control group isolates the impact of group characteristics on the intervention. The use of randomised controlled studies is frequently regarded as best practice in determining the impact of interventions (Grant et al. 2010). Grant (2013) reports that only 10\% of studies on the efficacy of coaching used control groups in the research design, of which half was randomised.

Mary et al. (2010) suggest that well-designed empirical research on EI, supplemented by research of a qualitative nature, may be useful in providing richer descriptions and a better understanding of the processes and outcomes of development interventions. This idea is echoed by Grant (2013, 2014) and McEnrue et al. (2010) who also highlight the benefits of grouping participants' experiences of the processes and outcomes of the interventions into broader meaningful themes.

The remaining part of this article focuses on applying the principles, as advocated by Groves et al. (2008), that an empirically sound research study on the impact of coaching on the ESCs of leaders should adhere to. In the next section, a theoretically substantiated coaching model is presented that is based on the principles of adult learning theory applicable to this study.

\section{An executive coaching model to develop emotional and social intelligence competencies}

Research evidence discussed thus far suggests that coaching is an effective leadership development technique. Executive coaching in particular is concerned with leader development within an organisational environment. Research done by Grant (2007:263) supports the notion that executives' EI can be changed through regular training sessions that focus on specific behaviours that are associated with EI.

Grant's (2007) empirical study involving spaced versus massed EI learning events indicate that frequent interventions over a longer term may be necessary to enhance EI. Literature on spaced learning supports this conclusion (Janiszewski, Noel \& Sawyer 2003). Research on spaced learning (distribution practice) versus massed learning that has been carried out over a period of more than a century demonstrates that learning benefits increase with increased time lags between learning events. It has been found that short and regular development sessions in combination with feedback are more effective than longer but less frequent sessions (Cepeda et al. 2009). Thus, coaches can facilitate deeper, more effective emotional learning through short learning episodes combined with a number of follow-up sessions than through long sessions of, say, 2 days without any follow-up sessions (Grant 2007).

According to Cherniss et al. (1998), emotional and social learning benefits from the setting of specific, clear and optimally challenging goals because the setting of such goals makes the most of motivation, mastery and self-efficacy. There is adequate theoretical support for the importance of goal setting in adult and self-regulated learning (Sitzmann \& Ely 2011). Fundamentally, self-regulation is about the capability to set and work towards goals. The coach assists clients to identify and create potential solutions to problems, outlines a range of goals and options and then facilitates the development and endorsement of action plans to accomplish these goals (Grant 2010:94).

The multidimensional nature of adult learning calls for a more holistic and contextualised approach to learning (Merriam 2008) and, therefore, for an integrative coaching model. However, existing coaching models are characterised by a lack of fertilisation across different coaching theories, thereby depriving the executive coach of a holistic model as a directive within an organisation (Passmore 2007:68). Passmore (2010) suggests the use of integrated models rooted in different schools of psychological thought, such as human behaviour and behavioural change theories (solution-focused coaching), behaviourism (the GROW model), constructive developmental psychology (developmental coaching) and cognitive psychology (cognitive behavioural coaching). Such integrated models offer the coach diverse ways in which to work by combining tools and techniques from different approaches and working at multiple levels in the organisation with the aim of building leaders' ESCs and consequently equipping them to achieve organisational goals.

According to Passmore (2007), the development of a holistic executive coaching model that incorporates multiple models should be the focus of future developments and less emphasis should be placed on a single coaching model. 
The arguments presented in the preceding paragraphs formed the foundation of the holistic coaching model (see Figure 1) that was developed by the primary author of this article to enhance the ESCs of leaders in the workplace. The aim of this model was to combine distinctly different coaching approaches and blend these to meet the coaching needs of leaders. The effective blending of the elements, tools and techniques of the different coaching approaches required an understanding and appreciation of the application value of each of the relevant coaching models.

In designing the holistic coaching model, the following models, frameworks, techniques and principles were considered: Bar-On's model of EI, the framework for emotional learning developed by Cherniss et al. (1998), practices applied in the science of emotion and interpersonal communication (Carey et al. 2011; Leskiw \& Singh 2007), Passmore's (2007) integrative coaching model, and the principles and best practices that lie at the core of various leadership development programmes (Brown 2010; Neenan 2010; Popper 2005; Turner \& Goodrich 2010). The following criteria were considered when selecting the theoretical coaching models to be reviewed for the development of the holistic coaching model:

- Theoretical inclusivity (Grant 2006:18): A range of psychological schools of thought were integrated (Passmore 2010:157).

- Wide acknowledgement in literature (Passmore 2010): The coaching models had been cited a significant number of times.

- Client-compatible, theoretically grounded techniques (Grant 2006:18): The coaching models offered theoretically grounded techniques to assist coaches in understanding and implementing the models so as to best help their clients in reaching their goals (Alexander 2010:87; Grant 2010:100; Neenan 2010:115; Passmore 2010:166).

- Potential to enhance performance in a business context (Grant et al. 2009:396): The coaching models were acknowledged as organisational interventions to develop leadership (Alexander 2010; Passmore 2010; Visser \& Butler 2008).

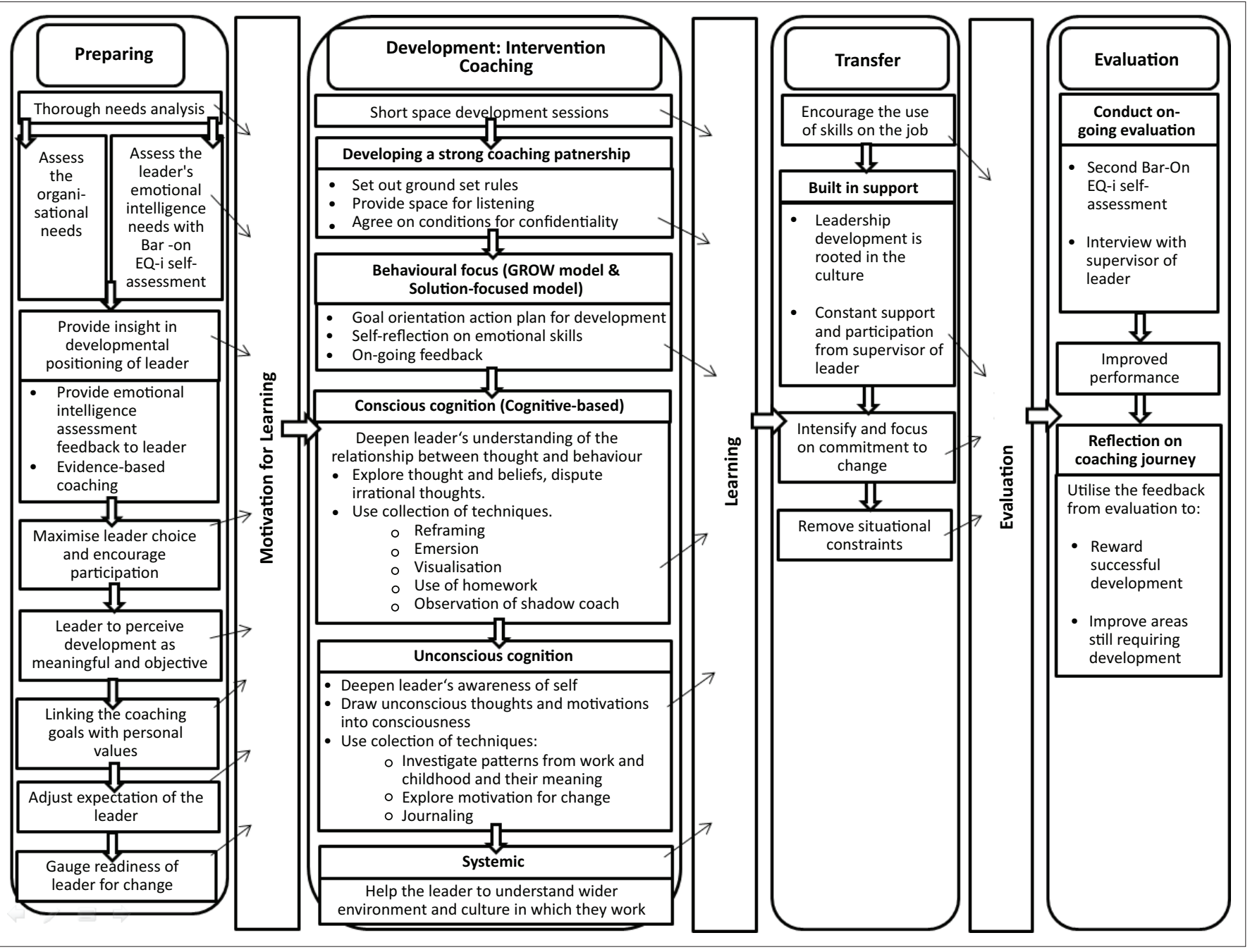

Source: Addapted from Bar-On, R., 2006, 'The Bar-On model of emotional-social intelligence (ESI)', Psicothema 18(Suppl. 1), 13-25; Cherniss, C., Goleman, D., Emmerling, R., Cowan, K. \& Adler, M., 1998, Bringing emotional intelligence to the workplace: A technical report issued by the Consortium for Research on Emotional Intelligence in Organizations, viewed 12 February 2013 , from http:// www.eiconsortium.org/reports/technical_report.html; Passmore, J., 2010, Excellence in coaching: The industry guide, 2nd edn., Kogan Page, London; and Turner, R.A. \& Goodrich, J., 2010, 'The case for eclecticism in executive coaching: Application to challenging assignments', Consulting Psychology Journal: Practice and Research 62(1), 39-55. https://doi.org/10.1037/a0018650

FIGURE 1: A holistic coaching model for use by the executive coach. 
The holistic coaching model is depicted in Figure 1, which is followed by a brief discussion.

The model depicted in Figure 1 consists of four phases:

- Phase 1: Preparing for coaching: motivation for change. The coaching focuses on motivating the leaders before the beginning of the learning process. The preparation consists of a thorough needs analysis at both the individual and organisational levels. Firstly, well-defined objectives of the ESC programme for leadership are developed at an organisational level. Next, the elements of successful emotionally intelligent leadership behaviour and the gaps in the leaders' behaviour in comparison with the ideal are identified at individual level. The evaluation methodology for initiating emotional learning is built on the Bar-On EQ-i assessment of the leaders.

- Phase 2: Development intervention. The second phase (the coaching intervention) specifically involves the change process. It consists of practices that support the leaders in changing their thinking, beliefs and behaviour to cope with emotional and social difficulties.

- Phase 3: Transfer. The third phase (transfer and maintenance) focuses on what occurs after the official coaching practice. The coach encourages the leaders to apply newly acquired ESCs in the work environment and to continue doing so.

- Phase 4: Evaluation. The last phase involves ongoing evaluation and feedback. The evaluation techniques include a follow-up Bar-On EQ-i assessment and feedback interviews with supervisors. Kirkpatrick's four-level model of training evaluation (reaction, knowledge, behaviour and results) was applied as an approach to determine and reflect on the effectiveness of the coaching intervention (Kirkpatrick \& Kirkpatrick 2005).

The main objective of this study was to empirically determine, describe and evaluate the impact of a theoretically substantiated holistic, longer term, spaced and goal-focused coaching intervention on the ESCs (as defined in the Bar-On model) of leaders in a financial services company in South Africa. In aspiring to achieve this objective, the researchers endeavoured to overcome design problems that inhibited research findings (problems found to be common to studies on EI development) and to provide a template to facilitate more informative studies on the impact of coaching on ESC.

\section{Research design Research approach}

A mixed method approach using qualitative and quantitative methods was used. Firstly, a quasi-experimental research design approach was followed using a non-equivalent preand post-control-group design to measure the impact of the coaching intervention. Thereafter, the impact of coaching was further investigated using qualitative methods and involving the experimental group and the relevant supervisors.

\section{The coaching intervention}

The coaching intervention was conducted by the primary author of this article. This researcher is a professional coach, registered industrial psychologist and human behaviour specialist with more than 10 years of coaching experience. The coaching model presented in Figure 1 was interpreted and converted into 16 design principles that were followed to guide and inform the coaching process (see Appendix 1). The design of the coaching intervention process is displayed in Figure 2, which is followed by a brief discussion of the process.

The coaching preparation phase consisted of a thorough needs analysis to establish a connection with business strategy (Leskiw \& Singh 2007), individual strengths and development areas based on the Bar-On EQ-i results. The coaching needs were linked to goal-orientated action plans (Brown 2010).

The coaching intervention process consisted of a regulated series of nine short coaching development sessions spaced over a period of approximately 9-12 months. The spacing of the coaching sessions granted leaders the opportunity to process and integrate their learning, thereby enhancing their ESCs. The coaching was conducted through one-on-one interactions, driven by the results of the Bar-On EQ-i report of the leaders and based on mutual trust and respect.

\begin{tabular}{|c|c|c|c|c|c|c|c|c|}
\hline \multicolumn{9}{|c|}{ Coaching sessions } \\
\hline $\begin{array}{c}\text { Session 1: } \\
\text { - Develop coaching } \\
\text { partnership. } \\
\text { - Set clear goals. } \\
\text { - Review behaviour } \\
\text { assessed using Bar- } \\
\text { On EQ-i } \\
\text { - Develop specific } \\
\text { action plan for } \\
\text { coaching. }\end{array}$ & $\begin{array}{l}\text { Session 2: } \\
\text { - Explore experiences } \\
\text { in childhood and } \\
\text { relationships leaders } \\
\text { had with caregivers } \\
\text { which contributed to } \\
\text { the development of } \\
\text { emotions. } \\
\text { - Introduce concepts } \\
\text { of journaling, } \\
\text { homework } \\
\text { and shadowing. }\end{array}$ & $\begin{array}{l}\text { Session 3: } \\
\text { Focus on self- } \\
\text { regard } \\
\text { and emotional } \\
\text { self-awareness. }\end{array}$ & $\begin{array}{c}\text { Session 4: } \\
\text { Focus on } \\
\text { independence, } \\
\text { assertiveness and } \\
\text { self-actualisation. }\end{array}$ & $\begin{array}{l}\text { Session 5: } \\
\text { Focus on } \\
\text { empathy, } \\
\text { interpersonal } \\
\text { relationships } \\
\text { and social } \\
\text { responsibility. }\end{array}$ & $\begin{array}{c}\text { Session 6: } \\
\text { Focus on stress } \\
\text { tolerance and } \\
\text { impulse control. }\end{array}$ & $\begin{array}{l}\text { Session 7: } \\
\text { Focus on } \\
\text { reality testing, } \\
\text { flexibility } \\
\text { and problem- } \\
\text { solving. }\end{array}$ & $\begin{array}{c}\text { Session 8: } \\
\text { Focus on } \\
\text { happiness and } \\
\text { optimism. }\end{array}$ & $\begin{array}{l}\text { Session 9: } \\
\text { Reflection on } \\
\text { overall } \\
\text { coaching } \\
\text { journey. }\end{array}$ \\
\hline
\end{tabular}

FIGURE 2: The design of the coaching intervention process. 
According to Mary et al. (2010), trainers should consider the support they offer to learners in the form of coaching and feedback as an important element of the design and application of an EI training study. In line with the coaching model, certain strategies were included such as ongoing feedback to leaders to give an indication whether they were heading in the right direction (Cherniss et al. 1998) and shadowing of leaders in selected meetings and discussions (Turner \& Goodrich 2010). This offered a platform for coaches to share observations on how effectively the leaders applied ESCs in the selected meetings and discussions.

In the transfer phase, leaders were required to use new behaviours regularly over a couple of months while receiving the built-in support of their supervisors. The programme was evaluated using a post-intervention Bar-On EQ-i assessment and conducting interviews with the supervisors.

Next, the quantitative and qualitative phases used in this study to determine the impact of coaching are discussed.

\section{Phase 1: The quantitative research design}

\section{Population, sample, questionnaire, data collection and analysis techniques}

Leaders in a financial services company in the South African business context made up the target population of the study. These leaders were typically team leaders, middle managers or senior managers.

The experimental group consisted of 30 participants in a randomly chosen voluntary coaching programme for leaders. The 30 members of the control group were sourced from the company's internal recruitment assessment database consisting of leaders who had completed the Bar-On EQ-i for selection purposes. The latter group of leaders was randomly selected using stratified sampling according to age, race and gender. Each member of the experimental and control groups had completed the Bar-On EQ-i self-report questionnaire as a pre- and post-intervention measure of ESCs.

The Bar-On EQ-i self-report questionnaire consists of 133 items and a five-point anchored Likert scale. The EQ-i composite score represents a total EQ measurement and consists of main components and sub-components. (Descriptions of the EQ-i components were presented in the 'The Bar-On model of emotional intelligence' section).

The raw scores of the self-report questionnaire were converted into standardised scores of which the average score was 100 and the standard deviation was 15. Average to above average scores suggest that a respondent's emotional and social functioning can be considered effective whereas below average scores suggest an inability to be effective and the possible existence of emotional, social and / or behavioural problems.

The EQ-i measure is computer scored and contains a correction factor that automatically corrects scale scores based on responses to positive and negative impression items (Bar-On 2006). This procedure reduces the potentially negative effect of response bias and increases the accuracy of the scale scores.

Evidence of the reliability and validity of the Bar-On EQ-i's scale in a South African context can be considered acceptable and comparable, with values ranging between 0.67 and 0.92 obtained elsewhere (Bar-On 1997; Gallant 2005:11). On average, a total EQ reliability of 0.95 is very good (Ekermans et al. 2011; Gignac \& Ekermans 2010). The structural validity of the EQ-i had been confirmed for various South African sample groups (Ekermans et al. 2011; Gignac \& Ekermans 2010), and according to Kotzé and Venter (2011:408), adequate evidence exists of the criteria-related validity across several countries.

The statistical analysis was done using the Statistical Package for Social Sciences (SPSS) for Windows (Version 17.0). The difference in difference (DD) or double difference score analysis was considered to be the appropriate statistical method to use. DD is defined as the difference in mean outcome in respect of the experimental group before and after intervention minus the difference in mean outcome in respect of the control group before and after intervention. The DD equation would be:

$\hat{\delta}_{D D}=\overline{\mathrm{Y}}_{1}^{E}-\overline{\mathrm{Y}}_{0}^{E}-\left(\overline{\mathrm{Y}}_{1}^{C}-\overline{\mathrm{Y}}_{0}^{C}\right)$

where $E$ is the treatment group and $C$ is the control group $(0=$ pretest $; 1=$ posttest $)$.

The DD score analysis method removes the difference in the outcome between the experimental and the control groups at the baseline, allowing for an unbiased estimate of the intervention effect (May 2012). The Wilcoxon's statistic and the associated z-approximation were used to determine the significance of the differences on the difference score analysis (after Bonferroni adjustments had been made) over the 18 -month period. The meaningfulness of the differences was evaluated using Cohen's effect size indicators for $r$ (Cohen 1988). Practically meaningful levels of $r$ are $0.1=$ small effect, $0.3=$ medium effect and $0.5=$ large effect. The equation used for calculating $r$ was (Field 2005):

$r=\frac{Z}{\sqrt{\mathrm{N}}}$

where $\mathrm{Z}=\mathrm{z}$ score approximation for the Wilcoxon statistic; $N=$ total sample size (experimental and control group).

A comparative analysis of the biographical variables of the experimental and control groups was done using Pearson's chi-square test to provide evidence of the level of equivalence of the two groups. Furthermore, to explore group response biases (positive or negative impression forming), a comparative analysis of the pretest results in respect of the experimental and control groups was done. 


\section{Phase 2: The qualitative research design Population, sample, data collection and analysis techniques}

Participants considered for the qualitative phase consisted of two groups: leaders who had been exposed to coaching (experimental group) and the supervisors of those leaders. The primary author of this article conducted in-depth semistructured interviews with the six leaders of the experimental group and their supervisors (all in all 12 interviews). Table 2 presents the broad interview guide that outlines the proposed main and probing questions. The flow and contents of a discussion determined the structure and sequence of the questions posed. Supplementary questions were formulated when needed to ensure the collection of rich data.

The interviews were audio recorded and transcribed (Saunders, Lewis \& Thornhill 2009:485), after which the transcripts were read closely to verify the data obtained and to get an initial sense of the issues raised. Phrases that occurred regularly and responses that were unexpected or counterintuitive were noted (Miles \& Huberman 1984:22). The interview transcripts were sanitised (leaving out all names and references) before importing the data into the ATLAS.ti qualitative data analysis software program for coding and further processing. Open coding (breaking down, examining, comparing, conceptualising and categorising data) and axial coding (categorising codes and identifying patterns and relationships) were used (Strauss \& Corbin 2007:61). Subthemes that emerged were escalated to main themes. According to Boyatzis (1998:4), a theme is an identified pattern in the data that explains the probable interpretations or particular components of a research problem. In the following section, the findings of the quantitative and qualitative analyses will be presented.

TABLE 2: Interview guide for the leaders and their supervisors.

\begin{tabular}{|c|c|}
\hline Main & Probe for \\
\hline $\begin{array}{l}\text { What does emotional intelligence mean } \\
\text { to you? }\end{array}$ & $\begin{array}{l}\text { A solid theoretical framework and good } \\
\text { understanding of emotional intelligence. }\end{array}$ \\
\hline $\begin{array}{l}\text { What do you perceive was the impact } \\
\text { of longer-term, spaced and goal- } \\
\text { focused coaching on your/the } \\
\text { leader's emotional skills? }\end{array}$ & Specific examples and situations. \\
\hline $\begin{array}{l}\text { What do you consider to be the positive } \\
\text { outcomes of and benefits derived from } \\
\text { the coaching journey? }\end{array}$ & $\begin{array}{l}\text { For you and the leader? } \\
\text { For your and the leader's relationships? } \\
\text { For the business? }\end{array}$ \\
\hline $\begin{array}{l}\text { Were there any of your or the leader's } \\
\text { emotional intelligence skills that were } \\
\text { not enhanced by longer-term, spaced } \\
\text { and goal-focused coaching? }\end{array}$ & $\begin{array}{l}\text { If so, why? } \\
\text { Specific examples. }\end{array}$ \\
\hline $\begin{array}{l}\text { *How did you experience the coaching } \\
\text { journey? }\end{array}$ & $\begin{array}{l}\text { The coaching process? } \\
\text { The coaching relationship? }\end{array}$ \\
\hline $\begin{array}{l}\text { What could be the factors that might } \\
\text { have influenced the effectiveness of } \\
\text { the coaching journey? }\end{array}$ & $\begin{array}{l}\text { Examples of the factors contributing } \\
\text { to the effectiveness of coaching. } \\
\text { Examples of the factors hindering } \\
\text { coaching to be effective. }\end{array}$ \\
\hline $\begin{array}{l}\text { Is there anything else that you think may } \\
\text { be important that we have not discussed? }\end{array}$ & - \\
\hline
\end{tabular}

\section{Ethical consideration}

The Ethics Committee of the Faculty of Economic and Management Sciences, University of Pretoria approved the study.

\section{Discussion Quantitative findings}

The Bar-On EQ-i overall score, composite scales and factors were used to determine the impact of the coaching intervention on leaders' ESCs. The Pearson's chi-square test results were non-significant $(p>0.05)$, showing that the experimental and control groups appeared to be uniform in respect of gender, race, age and pretest scores, which eliminated the effect of these variables (see display in Table 3) on the internal validity of the research results.

The pretest and posttest scores for all components of the EQ-i in respect of the experimental and control groups are presented in Table 4. The Wilcoxon's statistic and the associated z-approximation showed that there were no statistically significant differences (all $p$-values $>0.05$ ) between any of the pretest scores of the experimental and control groups (z-approximation values for pretest score differences were not presented in Table 4 because of space restrictions). The mean total EQ-i score and component scores for all the pretests in respect of both groups were close to the standardised mean $(x=100)$, representing the EQ-i standardisation sample scores well. The small deviations observed could most likely be attributed to sampling error. As far as the pretests were concerned, these results confirmed the absence of notable response bias at group level.

The effect of the coaching intervention on the experimental group was evidenced by the DD score analyses which reflect in the significance of the $\mathrm{Z}$ scores (see Table 4). In respect of the two groups, the following Bar-On EQ-i main component scales differed significantly after allowing for Bonferroni adjustments $(p \leq 0.01)$ (Cohen's $(r)$ effect size indicators are given in brackets: see equation 2 in the 'The coaching intervention' section for the calculation of $r$ ):

- Total EQ ( $r=0.56$ : large effect)

- Intrapersonal ( $r=0.51$ : large effect)

- Interpersonal ( $r=0.37$ : medium effect)

- Stress management ( $r=0.34$ : medium effect)

The following Bar-On EQ-i sub-component scores differed significantly in respect of the two groups after allowing for Bonferroni adjustments $(p \leq 0.003)$ :

- Self-regard ( $r=0.42$ : medium to large effect)

- Empathy ( $r=0.38$ : medium effect)

TABLE 3: Biographical variable frequencies for the control and experimental groups $(N=30)$.

\begin{tabular}{|c|c|c|c|c|c|c|c|}
\hline \multirow[t]{2}{*}{ Frequencies } & \multicolumn{4}{|c|}{ Race } & \multicolumn{2}{|c|}{ Gender } & \multirow{2}{*}{$\begin{array}{c}\text { Age } \\
\text { Average }\end{array}$} \\
\hline & Black & Mixed race & Indian & White & Female & Male & \\
\hline Control group & 3 & 1 & 2 & 24 & 16 & 14 & 40 \\
\hline Experimental group & 1 & 1 & 6 & 22 & 16 & 14 & 39 \\
\hline
\end{tabular}


TABLE 4: Differences between the pre- and post-coaching evaluations of the experimental and control groups pertaining to the components measured $(N=30)$.

\begin{tabular}{|c|c|c|c|c|c|c|c|c|c|}
\hline \multirow[t]{3}{*}{ Components } & \multicolumn{4}{|c|}{ Control group } & \multicolumn{4}{|c|}{ Experimental group } & \multirow[t]{3}{*}{ Z } \\
\hline & \multicolumn{2}{|c|}{ Pretest } & \multicolumn{2}{|c|}{ Posttest } & \multicolumn{2}{|c|}{ Pretest } & \multicolumn{2}{|c|}{ Posttest } & \\
\hline & Mean & Std. dev. & Mean & Std. dev. & Mean & Std. dev. & Mean & Std. dev. & \\
\hline Intrapersonal & 101.83 & 13.58 & 99.17 & 14.47 & 104.23 & 11.60 & 108.50 & 9.95 & $3.94 * 5$ \\
\hline Self-regard & 101.57 & 11.85 & 96.87 & 12.20 & 104.17 & 12.02 & 105.47 & 9.77 & $3.21 * 15$ \\
\hline Emotional self-awareness & 97.87 & 15.23 & 96.00 & 14.54 & 102.30 & 13.43 & 106.97 & 12.46 & 2.36 \\
\hline Assertiveness & 99.37 & 16.81 & 100.2 & 14.36 & 101.60 & 12.57 & 105.87 & 12.30 & 1.63 \\
\hline Independence & 105.97 & 11.92 & 103.93 & 13.18 & 103.83 & 12.15 & 106.30 & 11.21 & 1.39 \\
\hline Self-actualisation & 101.40 & 11.84 & 98.27 & 14.07 & 103.57 & 12.42 & 106.97 & 9.99 & 2.63 \\
\hline Interpersonal & 98.80 & 12.33 & 97.33 & 13.63 & 99.63 & 12.04 & 105.77 & 11.63 & $2.88 * 5$ \\
\hline Empathy & 101.03 & 13.29 & 98.63 & 15.79 & 98.83 & 11.95 & 104.73 & 12.00 & $2.97 * 15$ \\
\hline Social responsibility & 102.07 & 13.32 & 99.57 & 14.82 & 98.17 & 14.10 & 103.87 & 12.25 & 2.39 \\
\hline Interpersonal relationship & 96.33 & 12.97 & 95.97 & 13.30 & 101.33 & 12.36 & 106.23 & 10.87 & 2.82 \\
\hline Stress management & 104.30 & 13.31 & 102.53 & 11.61 & 98.83 & 17.38 & 104.57 & 14.72 & $2.63 * 5$ \\
\hline Stress tolerance & 103.90 & 13.18 & 101.47 & 12.77 & 102.97 & 12.68 & 105.97 & 12.07 & 2.59 \\
\hline Adaptability & 104.27 & 13.82 & 102.47 & 12.60 & 102.83 & 12.79 & 103.97 & 21.93 & 2.30 \\
\hline Reality testing & 102.93 & 12.46 & 104.40 & 11.46 & 103.77 & 13.12 & 106.23 & 11.35 & 0.54 \\
\hline Flexibility & 101.47 & 15.41 & 98.00 & 13.03 & 102.27 & 14.74 & 106.27 & 13.66 & 2.54 \\
\hline Problem solving & 105.57 & 11.42 & 103.23 & 13.53 & 100.20 & 11.33 & 103.97 & 12.99 & 2.05 \\
\hline General mood & 99.00 & 12.33 & 99.13 & 12.04 & 103.80 & 12.59 & 107.47 & 10.62 & 1.69 \\
\hline Optimism & 99.97 & 11.99 & 99.43 & 11.91 & 102.8 & 13.72 & 106.40 & 11.87 & 2.39 \\
\hline Happiness & 98.77 & 12.93 & 99.70 & 11.81 & 104.3 & 13.79 & 107.40 & 9.76 & 0.41 \\
\hline Total EQ & 102.90 & 12.86 & 101.6 & 13.15 & 102.33 & 13.12 & 108.90 & 10.98 & $4.33 *$ \\
\hline
\end{tabular}

Std. dev, Standard deviation; Z, Z score approximation of the Wilcoxon statistic for the significance of DD value attributable to intervention: $\hat{\delta}_{D D}=\overline{\mathrm{Y}}_{1}^{E}-\overline{\mathrm{Y}}_{0}^{E}-\left(\overline{\mathrm{Y}}_{1}^{C}-\overline{\mathrm{Y}}_{0}^{C}\right)$, where $E$ is the treatment group and $C$ is the control group ( $0=$ pretest; 1 = posttest).

*, Difference is statistically significant for total emotional quotient: $p \leq 0.05$; $* 5$, Statistically significant difference after applying the Bonferroni adjustment for the five main component scales: $\left(\frac{0.05}{5}\right)$ : $p \leq 0.01$

*15, Statistically significant difference after applying the Bonferroni adjustment for the 15 sub-component scales: $\left(\frac{0.05}{15}\right): p \leq 0.003$.

The findings indicated that coaching had a statistically significant and practically meaningful positive impact on the total EQ, intrapersonal, interpersonal, stress management, self-regard and empathy dimensions of the EQ-i scale. The largest notable changes based on Cohen's effect size indicators occurred on the total EQ-i scores and on the intrapersonal component.

This quantitative phase of the study provided evidence that coaching was an effective approach to develop some of the most important ESCs of leaders as measured by the BarOn EQ-i scale (Syndell 2008). Boyatzis et al. (2013) indicate that in accordance with ESC models, the EI is susceptible to development in adults. This notion is supported by Dulewicz, Higgs and Slaski (2003) and Jaeger (2003) who report that Bar-On EQ-i assessments have provided evidence that training could bring about substantial changes in ESCs. Similarly, the current study demonstrated meaningful improvements in ESCs in respect of the experimental group.

However, Groves et al. (2008) caution that while some published and unpublished empirical research studies propose that EI can be developed, seemingly significant limitations in research design have caused reported results to be doubted. However, supplementing quantitative research with qualitative research may enhance the authenticity of research findings and provide richer descriptions of the processes and outcomes of the coaching intervention.

\section{Qualitative findings}

In studying the interview data, the researchers identified themes that described the impact of coaching from the perspectives of the leaders and their supervisors. Guided by a deductive approach they distinguished 5 main themes and 13 subthemes, which they arranged according to the conceptual correspondence between these themes and the Bar-On EQ-i composite and subscales. The themes reflected an overall improvement in intrapersonal skills, interpersonal skills, stress management, adaptability and general mood. The improvements were noted when compiling summative subtheme descriptions reflecting the actual responses of the participants interviewed. In these descriptions (see below), Bar-On's definition of each ESC (as cited in Prins 2007:82) was given first, followed by each respondent's description of the impact of the coaching intervention on each ESC. Unfortunately, this article cannot report extensively on the interview responses because of limited space but the coded interviews are available from the corresponding author. The said summative descriptions that supported the finding that the participants' responses relating to the main themes and subthemes reflected improvements in ESC are presented below. The main themes and subthemes are indicated in brackets and a few examples of actual interview responses are included for illustrative purposes.

Intrapersonal skills (self-regard, emotional self-awareness, assertiveness, independence and self-actualisation) can be defined as 'an enhanced understanding, expression and development of the inner self'. The respondents 
reported improved self-confidence and self-respect, better understanding and expression of emotions and the impact thereof on others, more assertiveness in communicating emotions, more self-directed and self-regulated thinking and actions, and improved understanding of and drive to achieve self-actualisation. Examples of the participants' responses relating to emotional self-awareness are:

'Well from before the coaching and after the coaching, definitely an improvement in my intrapersonal skills, particularly the selfawareness that was very big for me. You know, just the ability to be aware of what is going on before one can respond to the environment.' [Leader 2].

'And I think I have sensed that in the last six months or so, [Leader 2] has become a bit more reflective. She thinks about things first, she thinks about different ways of doing things. So, you just get the sense she now thinks before she speaks, whereas in the past she didn't always do that.' [Supervisor of Leader 2].

Interpersonal skills (empathy and interpersonal relationships) can be defined as 'an enhanced capacity for empathy and interpersonal functioning'. The respondents reported an improved ability to try to understand the feelings of others, enhanced listening skills, improved leader-team connection and engagement, openness to the opinions of others and feedback. Examples of the participants' responses relating to interpersonal relationships are:

'I think interpersonal relationships have improved. Previously, before the coaching I would say that my relationships were very much at arm's length. And maybe not, we were not interested in getting to know other people better, the person on the other side, but the coaching has given me some techniques... We have gone from the point of view that, you know this is an opportunity to have a private talk between two people and just open up any areas. And I think the end result of that was that I felt much more in tune with my staff.' [Leader 6].

'If I think about some of my interactions with staff, some of the feedback that I receive from them was that [Leader 6] now sets up a session with them, if he sees that there are concerns. He addresses it one-on-one.' [Supervisor of Leader 6].

Stress management (stress tolerance and impulse control) reflects 'the increased ability to withstand stressors without losing control or falling apart'. The respondents reported an improved understanding of and capacity to deal with stress, better management of volatile emotions and a deeper awareness of the triggers of impulses. Examples of the participants' responses relating to impulse control are:

'So if I am angry, somebody is demonstrating a behaviour that to me is irresponsible. This is a key indicator for me. I need to acknowledge that is what is happening and not try to not be angry that the person is irresponsible and choose when to respond. So when I identify my anger, I am now able to choose not to respond in the middle of that.' [Leader 3].

'And then the other area that I sensed improvement as well is definitely around self-control. I think in the past I have experienced her to be quite impulsive and she would quickly go off and say something and sort of tie a flare to the mast without really giving it a lot of thought first.' [Supervisor of Leader 3].
Adaptability (flexibility and problem solving) can be described as 'the ability to cope with environmental demands by being able to size up situations realistically and to deal with problematic situations'. The respondents reported an improved ability to adjust their emotions, thoughts and behaviours to changing situations and conditions, coupled with a better ability to define and solve problems.

General mood (optimism and happiness) reflects the individual's 'ability to enjoy life and a general level of contentment'. The respondents reported improved levels of being motivated, positive, happy and appreciative of experiencing the moment and an improved ability to engage with others.

Next, the themes were interpreted guided by an inductive coding approach. The main themes that emerged were 'the facilitators and obstacles to effective coaching', 'experiences of the coaching journey' and 'coaching outcomes'. Although the themes contained many insightful details about the coaching intervention, this discussion will be limited to a summary of the most important observations.

Adjusting an existing leadership style and being inclined to fall back on old styles emerged as possible difficulties hampering the success of a coaching intervention. Individual readiness factors, which include self-efficacy and receptivity to engage in EI development, behaviour change and coaching in general, may also play a role in determining the success of an intervention (Groves et al. 2008; Passmore \& FilleryTravis 2011). Furthermore, if organisational and supervisor support is not sustained and EI skills are not practised sufficiently, leaders may transgress to their 'starting points' (Nelis et al. 2009).

The leaders experienced the coaching journey as valuable, enjoyable, relevant and impactful. They described their relationships with their coaches as positive and supportive and their coaches as knowledgeable and open-minded. A good coaching partnership is fundamental in facilitating change and growth within leaders (Carey et al. 2011).

Overall, the outcome of the coaching process was considered to be positive. The general theme that emerged was that leadership was effective, interpersonal skills had improved, the relationship between team members was one of trust and support and enhanced ESCs would contribute to organisational success. These results corroborate the findings of studies (as cited in Van Oosten 2013:16) in which the notion is supported that effective leadership is associated with the relationship between ESCs and leadership behaviour. However, the complete translation of emotional and social intelligence knowledge into behaviour may still be problematic for specific individuals.

Trustworthiness of the qualitative research findings was achieved through triangulation, credibility and member checking. Triangulation was attained through exploring the 
views of the leaders and their supervisors and determining which views they shared or did not share. Credibility was ensured by making voice recordings of the responses of participants representing diverse leaders who had different thoughts about EI skills and coaching. Member checking was applied to obtain interviewees' confirmation of the recorded data and the interpretation thereof. Ambiguities or misunderstandings were cleared up, and a printed copy of the findings was presented to each interviewee for confirmation (Guion, Diehl \& McDonald 2011).

\section{Synthesis of the research findings}

Both the quantitative and qualitative data gathered in this study showed that the coaching intervention had had a positive impact on the ESCs of the participating leaders in a financial services company.

The qualitative nature of the theme descriptions provided rich data that assisted with the conceptualisation of the changes brought about by the intervention, and the qualitative data enriched the statistical findings in the quantitative phase of this study.

The most notable finding in the quantitative phase, which was supported by the qualitative findings, was the significant positive impact EI coaching had on the intrapersonal, interpersonal, stress management, self-regard and empathy components of Bar-On's model of ESCs. These components have important implications as far as leadership effectiveness is concerned. Syndell (2008) reports that the EQ-i intrapersonal component, which includes self-regard and empathy, is the most significant predictor of a transformational leadership style. The second most important predictor is general mood, and the interpersonal component is also important but to a lesser degree. However, Kotzé and Venter (2011) have identified the interpersonal and stress management components as important differentiators of effective leadership. Maintaining healthy and satisfying interpersonal relationships, showing empathy by being sensitive to the what, how and why of people's feelings and contributing to the group's well-being are critical for leadership success. Stein et al. (2009) report that leaders possessing higher levels of self-regard (to accurately perceive, understand and accept oneself) and empathy are more likely to yield high-profit earnings for companies.

The qualitative results suggested that, besides social responsibility and reality testing that never emerged as relevant themes, all the components and sub-components that contributed to the EQ-i scale showed improvements. Researchers have generally recognised the importance of all the EQ-i components as factors contributing to leadership success (Kotzé \& Venter 2011; Stein et al. 2009). The inductive coding results discussed earlier revealed that, despite the challenges identified, the coaching process was generally considered positive and the likely impact thereof on effective leadership was recognised by the participants in the study.

\section{Contribution of the study}

The results of this study have significance for academic research, the profession of executive coaching, the practice of leadership development, and organisations in general. The research results support the effectiveness of a holistic, longer term, spaced and goal-focused coaching intervention as a means to develop the ESCs of leaders in a financial services company in South Africa.

As mentioned earlier in the article, the study aimed to address the following restrictive issues that Groves et al. (2008) have identified in existing experimental EI development studies:

- EI conceptual and assessment concerns. The focus of this study was on ESCs in respect of which adequate support exists for the reliability and validity of the EQ-i that measures emotional and social functioning. A factor in this study that most likely mitigated the effect of positive social desirability was the built-in correction formula for biased scores based on positive and negative impression item responses.

- A lack of information concerning the training intervention. As this study clearly described the key elements and principles of the coaching model and the design of the holistic coaching programme, it would be particularly valuable for use by those engaged in training and research. A more detailed description, which was not possible in this article because of limited space, may be obtained from the corresponding author.

- Short duration of the training intervention. In this study, a more in-depth and effective emotional learning intervention could be presented as it consisted of a regulated series of nine coaching sessions spaced over a period of 9-12 months. The leaders could consistently practise their newly acquired EI behaviours in their work and home environments during this period.

- Absence of essential statistical controls and/or a control group. Owing to the non-randomised control group design used in this study, the experimental and control groups could not be considered equal in all respects. However, the stratified sampling technique used ensured that the control group closely resembled the experimental group with respect to race, gender and age. The results of the statistical analyses confirmed the equivalence of the two groups with respect to these attributes. Therefore, the potential effects of race, gender and age were isolated from the intervention.

The value of supplementing quantitative research evidence with qualitative research evidence in the form of meaningful subthemes that support the quantitative findings was demonstrated in this study. According to Lincoln and Guba (1985:316), the transferability of qualitative research to other contexts depends on the thickness of description of the research approach and design. The description in this study was such that other researchers would be able to understand the approach and design and apply these with relative confidence to their own contexts. 
Factors that most likely contributed to the success of the coaching intervention were the following: (1) It specifically focused on the development of ESCs that was relevant to the outcome, namely, effective leadership behaviour. (2) It involved longer term, regular and short coaching interventions to facilitate deeper, more effective EI improvement, which contributed to the effectiveness of the leaders (McEnrue et al. 2010). (3) It incorporated the main design elements and best practices applied in the fields of adult learning and leadership development, which resulted in more effective leadership development (McEnrue et al. 2010). (4) It brought together distinct coaching models and merged these into a holistic approach designed to focus on the coaching requirements of leaders (Passmore 2007).

Research has shown that more effective leadership is needed to increase organisational performance. Judging from academic contributions, effective leaders use more EI skills than do less effective leaders (Coetzee \& Schaap 2005; Goleman 1998; Kotzé \& Venter 2011). The current research study provides the organisation with a coaching model that can be used to improve the ESCs of its leaders, in that way making these leaders more effective.

\section{Limitations}

As is the case with all studies, this study had its limitations, and these are acknowledged by the authors.

The use of self-reporting questionnaires increased the risk of leaders responding to the questionnaires in a socially desirable way, which might have affected the construct validity of the study. However, the built-in response bias correction formula discussed earlier might have had a mitigating effect. The EQ-i questionnaire was initially completed by the control group in a high-stakes situation as the measure formed part of a pre-employment selection battery, whereas the second application (posttest) did not take place in a high-stakes situation. Dunlop, Telford and Morrison (2012) indicate that the high-stakes testing is particularly susceptible to socially desirable responses. If social desirability was evident, it would have been reasonable to expect high pretest scores and lower posttest scores in respect of the control group. This was not the case as the control group's overall pretest and posttest scores did not differ significantly. Furthermore, the pretest mean scores of both the experimental and the control groups did not deviate markedly from the EQ-i standardisation sample mean score $(X=100)$. Irrespective of the arguments put forward, the possible effect of socially desirable responses on the results could not be negated completely considering that the leaders who received coaching participated willingly and might have been highly motivated to see the coaching succeed.

Furthermore, the context and purpose of the post-assessment in respect of the experimental and the control groups differed. Considering the experimental group's enhanced knowledge of the constructs measured, posttest scores might have been a reflection of construct knowledge rather than of true behavioural changes (Dunlop et al. 2012). However, evidence obtained from the qualitative research component did suggest EI behavioural changes in the experimental group, which somewhat reduces the possibility that these changes could be ascribed to distorted assessment scores. It should be noted though that the subjective nature of the qualitative research process, the involvement of one of the researchers in the coaching intervention and this researcher's evaluation of the interview data might have influenced the qualitative findings. However, to minimise subjectivity this researcher used well-recognised procedures, which included triangulation, credibility and member checking.

The quasi-experimental design used for the purposes of this study might have resulted in variables other than race, gender and age to influence the outcome of the study. The qualitative research results did, however, indicate that meaningful changes ascribed to the intervention had taken place.

\section{Research recommendations}

The following recommendations for future research could be made in the interest of advancing the practice and profession of coaching and broadening the knowledge base in coaching as an approach to develop the EI of leaders:

- To validate the impact of coaching on the EI of leaders over time, more longitudinal empirical research should be conducted using randomised experimental and control group studies.

- Given the problems inherent in self-report assessments (which were applied in this study to measure the EI of the leaders), the Bar-On EQ-i 360-degree assessment should be used in future research. This type of assessment would allow superiors, peers, and/or followers to rate participative leaders on relevant characteristics. A significant variance between self-evaluation and the evaluation of others might give a better indication of whether or not participative leaders' perceptions of their leadership style are accurate (Syndell 2008).

\section{Conclusion}

The professional practice of coaching as part of the discipline of leadership development is new and still evolving. It is posited that coaching as a leadership development strategy has nevertheless already been proven to be effective and to produce various positive outcomes. Despite the evidence obtained from research that suggests that executive coaching may be an effective leadership development strategy, insufficient research has been done that demonstrates the impact of theoretically substantiated and appropriately designed coaching interventions on the ESCs of leaders. It has been broadly articulated that adequate theory building in respect of the effectiveness of specific development processes and outcomes is dependent on a sufficient number of welldesigned and informative research studies (Groves et al. 2008; Jones et al. 2016; Theeboom et al. 2014). This study aimed to develop a template of what can be considered an 
informative study on the impact of coaching on the emotional and social intelligence competencies of leaders. Empirical evidence obtained in this study strongly suggests that the well-described and theoretically substantiated longer term, spaced and goal-focused coaching intervention that was implemented had a positive impact on the ESCs of leaders in a financial services institution. However, the implications of the limitations applicable to this study could have influenced the findings, and future research aimed at improving relevant research models should take these into account. Coaching leaders in emotional effectiveness is an exciting field that offers vast opportunities for further research and practical application. The coaches, the organisations that engage in coaching, the leaders who are coached and the academics who research the coaching process are all breaking new ground in this growing field.

\section{Acknowledgements Competing interests}

The authors declare that they have no financial or personal relationships that may have inappropriately influenced them in writing this article.

\section{Author's contributions}

M.D. conceptualised the study, did an initial literature review, developed the coaching model, planned and executed the interventions, did the empirical data gathering and qualitative analyses and presented the findings as part of a doctoral degree study under supervision of the second author. She provided the first draft of the article and later made inputs on the reviewed versions of the article. P.S. wrote the article for publication with major revisions and updates of the literature component, refined the presentation of the methodology section, conducted the statistical analyses, updated and refined the overall presentation and structure of article and wrote the discussion of the results and the various concluding sections of the article.

\section{References}

Alexander, G., 2010, 'Behavioural coaching - The GROW model', in J. Passmore (ed.), Excellence in coaching: The industry guide, 2nd edn., pp. 83-92, Kogan Page, London.

Bar-On, R., 1997, The emotional quotient inventory (EQ-i): A test of emotional intelligence, Multi-Health Systems, Toronto, Canada.

Bar-On, R., 2006, 'The Bar-On model of emotional-social intelligence (ESI)', Psicothema 18(Suppl. 1), 13-25.

Bartlett, J.E., Boylan, R.V. \& Hale, J.E., 2014, 'Executive coaching: An integrative literature review', Journal of Human Resource and Sustainability Studies 2(4) 188-195. https://doi.org/10.4236/jhrss.2014.24018

Bono, J.E., Purvanova, R.K., Towler, A.J. \& Peterson, D.B., 2009, 'A survey of executive coaching practices', Personnel Psychology 62(2), 361-404. https://doi.org/0.4236/ jhrss.2014.24018

Boyatzis, R.E., 1998, Transforming thematic analysis and code development, Sage, Thousand Oaks, CA.

Boyatzis, R.E., 2009, 'Competencies as a behavioral approach to emotional intelligence', Journal of Management Development 28(9), 749-770. https://doi. org/10.1108/02621710910987647

Boyatzis, R.E., Smith, M.L., Van Oosten, E. \& Woolford, L., 2013, 'Developing resonant leaders through emotional intelligence, vision and coaching', Organizationa Dynamics 42(1), 17-24. https://doi.org/10.1016/j.orgdyn.2012.12.003
Bozer, G. \& Sarros, J.C., 2012, 'Examining the effectiveness of executive coaching on coachees' performance in the Israeli context', International Journal of Evidence Based Coaching and Mentoring 10(1), 14-32.

Bresser, F. \& Wilson, C., 2010, 'What is coaching?', in J. Passmore (ed.), Excellence in coaching: The industry guide, 2nd edn., pp. 9-43, Kogan Page, London.

Brown, G., 2010, 'An exploratory study of the elements to develop a coaching model', Published doctoral thesis, Capella University, Minneapolis, MN, viewed 12 December 2012, from http://0-search.proquest.com.innopac.up.ac.za/docview/5 00018986? accountid $=14717$ /

Butler, C.J. \& Chinowsky, P.S., 2006, 'Emotional intelligence and leadership behavior in construction executives', Journal of Management in Engineering 22(3), 119-125. https://doi.org/10.1061/(ASCE)0742-597X(2006)22:3(119)

Carey, W., Philippon, D.J. \& Cummings, G.G., 2011, 'Coaching models for leadership development: An integrative review', Journal of Leadership Studies 5(1), 51-69. https://doi.org/10.1002/jls.20204

Cepeda, N.J., Rohrer, D., Wixted, J.T., Mozer, M.C. \& Pashler, H., 2009, 'Optimizing distributed practice: Theoretical analysis and practical implications', Experimental Psychology 56(4), 236-246. https://doi.org/10.1027/1618-3169.56.4.236

Cherniss, C., 2010, 'Emotional intelligence: Toward clarification of a concept', Industrial and Organizational Psychology 3(2), 110-126. https://doi.org/10.1111/ j.1754-9434.2010.01231.x

Cherniss, C., Goleman, D., Emmerling, R., Cowan, K. \& Adler, M., 1998, Bringing emotional intelligence to the workplace: A technical report issued by the Consortium for Research on Emotional Intelligence in Organizations, viewed 12 February 2013, from http://www.eiconsortium.org/reports/technical_report. hebrul

Coetzee, C. \& Schaap, P., 2005, 'The relationship between leadership behaviour outcomes of leadership and emotional intelligence', SA Journal of Industrial Psychology 31(3), 31-38. https://doi.org/10.4102/sajip.v31i3.207

Cohen, J., 1988, Statistical power analysis for the behavioral sciences, rev. edn., Academic Press, Orlando, CA

Daus, C. \& Ashkanasy, N., 2005, 'The case for an ability-based model of emotional intelligence in organizational behavior', Journal of Organizational Behavior 26, 453-466. https://doi.org/10.1002/job.321

De Meuse, K.P., Dai, G. \& Lee, R.L., 2009, 'Evaluating the effectiveness of executive coaching: Beyond ROI?', Coaching: An International Journal of Theory, Research and Practice 2(2), 117-134. https://doi.org/10.1080/17521880902882413

Downey, M., 2003, Effective coaching: Lessons from the coaches' coach, 3rd edn., Thomson Texere, New York.

Dulewicz, V., Higgs, M. \& Slaski, M., 2003, 'Measuring emotional intelligence: Content, construct and criterion-related validity', Journal of Managerial Psychology 18(5), 405-420. https://doi.org/10.1108/02683940310484017

Dunlop, P.D., Telford, A.D. \& Morrison, D.L., 2012, 'Not too little, but not too much: The perceived desirability of responses to personality items', Journal of Research in Personality 46(1), 8-18. https://doi.org/10.1016/j.jrp.2011.10.004

Ekermans, G., Saklofske, D.H., Austin, E. \& Stough, C., 2011, 'Measurement invariance and differential item functioning of the Bar-On EQ-i: S measure over Canadian, Scottish, South African and Australian samples', Personality and Individual Differences 50(2), 286-290. https://doi.org/10.1016/j.paid.2010.10.004

Gallant, S., 2005, EQ-i? South African norms, MHS Technical Report No. 0035, Research and Development. Jopie van Rooyen and Partners SA, Johannesburg, South Africa.

Gignac, G.E. \& Ekermans, G., 2010, 'Group differences in El within a sample of black and white South Africans', Personality and Individual Differences 49(6), 639-644. https://doi.org/10.1016/j.paid.2010.05.039

Goleman, D., 1995, Emotional intelligence, Bantam, New York.

Goleman, D., 1998, Working with emotional intelligence, Bantam, New York.

Grant, A.M., 2006, 'A personal perspective on professional coaching and the development of coaching psychology', International Coaching Psychology 1(1) $12-22$.

Grant, A.M., 2007, 'Enhancing coaching skills and emotional intelligence through training', Industrial and Commercial Training 39, 257-266. https://doi.org/10. 1108/00197850710761945

Grant, A.M., 2010, 'Solution-focused coaching', in J. Passmore (ed.), Excellence in coaching: The industry guide, 2nd edn., pp. 94-109, Kogan Page, London.

Grant, A.M., 2013, 'The efficacy of coaching', in J. Passmore, B.D. Peterson \& T. Freire (eds.), Handbook of the psychology of coaching and mentoring, pp. 15-39, Wiley, West Sussex.

Grant, A.M., 2014, 'The efficacy of executive coaching in times of organisational change', Journal of Change Management 14(2), 258-280. https://doi.org/10.1080/ 14697017.2013.805159

Grant, A.M., Curtayne, L. \& Burton, G., 2009, 'Executive coaching enhances goal attainment, resilience and workplace well-being: A randomised controlled study', Journal of Positive Psychology 4(5), 396-407, viewed 04 September 2011, from http://www.informaworld.com

Grant, A.M., Passmore, M., Cavanagh, M.J. \& Parker, H., 2010, 'The state of play in coaching today: A comprehensive review of the field', International Review of Industrial and Organizational Psychology 25, 125-67. https://doi.org/10. 1002/9780470661628

Green, M.E. 2002, 'Ensuring the organization's future: A leadership development case study', Public Personnel Management 31(4), 431-439. https://doi.org/10. 1177/009102600203100401 
Groves, S.K., Mcenrue, P.M. \& Shen, W., 2008, 'Developing and measuring emotional intelligence of leaders' Journal of Management Development 27, 225-250. intelligence of leaders', Journal of Manage
https://doi.org/10.1108/02621710810849353

Guion, L.A., Diehl, D.C. \& Mcdonald, D., 2011, Triangulation: Establishing the validity of qualitative studies 1, The Institution of Food and Agriculture Sciences, University of Florida, Gainesville, FL, viewed 11 May 2013, from http://edis.ifas. ufl.edu/fy394

Field, A.P., 2005, Discovering statistics using SPSS, 2nd edn., Sage, London.

Harms, P.D. \& Credé, M., 2010, 'Emotional intelligence and transformational and transactional leadership: A meta-analysis', Journal of Leadership and Organizational Studies 17(1), 5-17. https://doi.org/10.1177/1548051809350894

Hayward, B.A., 2005, 'Relationship between employee performance, leadership and emotional intelligence in a South African parastatal organisation', Unpublished master's thesis, Rhodes University, Grahamstown, viewed 30 March 2010, from http://eprints.ru.ac.za/302

Jaeger, A., 2003, 'Job competencies and the curriculum: An inquiry into emotion in graduate professional education', Research in Higher Education 44(6), 615-639. https://doi.org/10.1023/A:1026119724265

Janiszewski, C., Noel, H. \& Sawyer, A.G., 2003, 'A meta-analysis of the spaced effect in verbal learning: Implications for research on advertising repetition and consume memory', Journal of Consumer Research 30, 138-149. https://doi.org/10. 1086/374692

Jones, R.J., Woods, S.A. \& Guillaume, Y.R.F., 2016, 'The effectiveness of workplace coaching: A meta-analysis of learning and performance outcomes from coaching' Journal of Occupational and Organizational Psychology 89(2), 249-277. https:// doi.org/10.1111/joop.12119

Joseph, D.L. \& Newman, D., 2010, 'Emotional intelligence: An integrative metaanalysis and cascading model', Journal of Applied Psychology 95(1), 54-78. analysis and cascading model', Jour
https://doi.org/10.1037/a0017286

Kirkpatrick, D. \& Kirkpatrick, J., 2005, Evaluating training programs: The four levels, 3rd edn., Berrett-Koehler, San Francisco, CA.

Kotzé, M. \& Venter, I., 2011, 'Differences in emotional intelligence between effective and ineffective leaders in the public sector: An empirical study', International Review of Administrative Sciences 77(2), 397-427. https://doi.org/0.1177/ 0020852311399857

Leskiw, S. \& Singh, P., 2007, 'Leadership development: Learning from best practices', Leadership and Organization Development Journal 28(5), 444-464. https://doi. org/10.1108/01437730710761742

Lincoln, Y.S. \& Guba, E.G., 1985, Naturalistic inquiry, Sage, Newbury Park, CA.

Mary, B., Mcenrue, P., State, C., Groves, K.S., Citation, A., Pat, M. et al., 2010, 'Emotional intelligence training: Evidence regarding its efficacy for developing leaders', Leadership Review 10, 3-26.

May, H., 2012, 'Non-equivalent comparison group designs', in H. Cooper, P.M. Camic, D.L. Long, A.T. Panter, D. Rindskopf \& K.J. Sher (eds.), APA handbook of research methods in psychology, vol. 2, pp. 489-509. American Psychological Association, Washington, DC

Mayer, J.D., Roberts, R.D. \& Barsade, S.G., 2008, 'Human abilities: Emotional intelligence', Annual Review of Psychology 59, 507-536. https://doi.org/10.1146/ annurev.psych.59.103006.093646

Mayer, J.D., Salovey, P. \& Caruso, D., 2000, 'Emotional intelligence meets traditional standards for intelligence', Intelligence 27(4), 267-298. https://doi.org/10.1016/ S0160-2896(99)00016-1

Mccleskey, J., 2014, 'Emotional intelligence and leadership: A review of the progress, controversy, and criticism', International Journal of Organizational Analysis 22(1), 76-93. https://doi.org/10.1108/IJOA-03-2012-0568

Mcenrue, M.P., Groves, K.S. \& Shen, W., 2010, 'Emotional intelligence training: Evidence regarding its efficacy for developing leaders', Kravis Leadership Institute, Leadership Review 10(Winter), 3-26.

Merriam, S.B., 2008, 'Adult learning theory for the twenty-first century', New Direction for Adult and Continuing Education 119(Fall), 93-98. https://doi.org/10.1002/ ace.309

Miles, M. \& Huberman, A.M., 1984, Qualitative data analysis: An expanded sourcebook, 2nd edn., Sage, Thousand Oaks, CA.
Neenan, M., 2010, 'Cognitive behavioural coaching', in J. Passmore (ed.), Excellence in coaching: The industry guide, 2nd edn., pp. 110-122, Kogan Page, London.

Nelis, D., Quoidbach, J., Mikolajczak, M. \& Hansenne, M., 2009, 'Increasing emotional intelligence: (How) is it possible?', Personality and Individual Differences 47(1), 36-41, viewed 07 October 2014, from http://0-ac.els-cdn.com.innopac.up.ac.za/

Page, N. \& De Haan, E., 2014, 'Does executive coaching work?', Psychologist 27(8), 582-586.

Passmore, J., 2007, 'An integrative model for executive coaching', Consulting Psychology Journal: Practice and Research 59(1), 68-78. https://doi.org/10.1037/ 1065-9293.59.1.68

Passmore, J., 2010, Excellence in coaching: The industry guide, 2nd edn., Kogan Page, London.

Passmore, J. \& Fillery-Travis, A., 2011, 'A critical review of executive coaching research: A decade of progress and what's to come', Coaching: An International Journal of Theory, Research and Practice 4(2), 70-88. https://doi.org/10.1080/17521882.20 Theory, Rese $11.596484 \mathrm{n}$

Pillay, M., Viviers, R. \& Mayer, C., 2013, 'The relationship between emotional intelligence and leadership styles in the South African petrochemical industry', SA Journal of Industrial Psychology 39(1), 1-12. https://doi.org/10.4102/sajip. v39i1.1109

Popper, M., 2005, 'Main principles and practices in leader development', Leadership and Organization Development Journal 26(1), 62-75. https://doi.org/10. 1108/01437730510575598

Prins, A., 2007, 'Emotional intelligence and leadership in corporate management: A fortigenic perspective', Unpublished doctoral thesis, University of the Free State Bloemfontein, viewed 09 November 2013, from http://etd.uovs.ac.za/ETD-db/ theses/available/etd-08232007-153223/unrestricted/PrinsA.pdf

Prins, A., Van Niekerk, E. \& Weyers, A., 2011, Emotional intelligence: Tipping point in workplace excellence, Knowres, Randburg, South Africa.

Salovey, P. \& Mayer, J.D., 1990, 'Emotional intelligence', Imagination, Cognition and Personality 9, 185-211. https://doi.org/10.2190/DUGG-P24E-52WK-6CDG

Saunders, M., Lewis, P. \& Thornhill, A., 2009, Research methods for business students, 5th edn., Pearson Education, Harlow, Essex.

Schutte, N.S., Malouff, J.M. \& Thorsteinsson, E.B., 2013, 'Increasing emotional intelligence through training: Current status and future directions', International Journal of Emotional Education 5(1), 56-72, viewed 24 June 2015, from http:// www.um.edu.mt/ data/assets/pdf file/0005/183884/vol5i1p4.pdf

Sitzmann, T. \& Ely, K., 2011, 'A meta-analysis of self-regulated learning in work-related training and educational attainment: What we know and where we need to go', Psychological Bulletin 137(3), 421-442. https://doi.org/10.1037/a0022777

Stein, S.J., Papadogiannis, P., Yip, J.A. \& Sitarenios, G., 2009, 'Emotional intelligence of leaders: A profile of top executives', Leadership and Organization Development Journal 30(1), 87-101. https://doi.org/10.1108/01437730910927115

Strauss, A.L. \& Corbin, J., 2007, Basics of qualitative research. Techniques and procedures for developing grounded theory, 3rd edn., Sage, Thousand Oaks, CA.

Syndell, M.A., 2008, 'The role of emotional intelligence in transformational leadership style', Doctoral dissertation, Capella University, Minneapolis, MN, viewed 03 March 2014, from http://pqdtopen.proquest.com/pqdtopen/doc/304816657. html?FMT=ABS

Theeboom, T., Beersma, B. \& Van Vianen, A.E.M., 2014, 'Does coaching work? A metaanalysis on the effects of coaching on individual level outcomes in an organizational context', Journal of Positive Psychology 9(1), 1-18. https://doi.org/10.1080/1743 context', Journal of
9760.2013 .837499

Thorndike, E.L., 1920, 'A constant error in psychological ratings', Journal of Applied Psychology 4, 25-29. https://doi.org/10.1037/h0071663

Turner, R.A. \& Goodrich, J., 2010, 'The case for eclecticism in executive coaching: Application to challenging assignments', Consulting Psychology Journal: Practice and Research 62(1), 39-55. https://doi.org/10.1037/a0018650

Van Oosten, E.B., 2013, 'The impact of emotional intelligence and executive coaching on leader effectiveness', Unpublished doctoral thesis, Case Western Reserve University, Cleveland, $\mathrm{OH}$

Visser, C. \& Butler, R., 2008, 'The effectiveness of solution-focused working in coaching and consultancy', Gedrag en Organisatie 21(1), 35-55. 


\section{Appendix 1 \\ The design of the coaching process}

The coaching model was interpreted and translated into 16 design principles which were followed to guide and inform the coaching process, as discussed below.

\section{Design principles of the preparation phase:}

- Assessment of the organisational needs - The objectives of the emotional intelligence (EI) coaching intervention for leaders were determined by assessing the organisational needs (Leskiw \& Singh 2007). This established a clear connection of the coaching intervention to the business strategy.

- Self-assessments - The leaders completed the Bar-On EQ-i assessment at the beginning of the coaching process to identify areas of strengths and developmental needs and at the end of the coaching process to evaluate the impact of the coaching on the El.

- Provide insight in developmental positioning of leader-Based on the results of the comprehensive El assessments, the coach and leaders agreed on the leaders' El developmental positioning and their coaching needs in pursuit of their goalorientated action plans (Brown 2010).

Design principles of the development phase:

- Series of short, spaced development sessions - A regular series of short, spaced coaching development sessions in combination with feedback was used to enhance El (Grant 2007). The coaching sessions were spaced over time to grant leaders the opportunity to process and integrate their learnings, thereby enhancing their El skills (Cherniss et al. 1998).

- Strong coaching partnership - The coach established an open, trusting, non-judgemental and supportive coaching relationship with the leaders. The coaching partnership played a fundamental role in facilitating change and growth within the leaders (Carey et al. 2011).

- Goal-orientated action plan for development - The coach assisted the leaders to set clear emotional skill development goals after reviewing their behaviour based on the evidence from the Bar-On EQ-i assessment. The GROW model provided a structure to compose a goal-orientated action plan for development (Downey 2003).

- Self-reflection on emotional skills - The coach guided the leaders through a process of self-reflection to create conscious awareness of the meaning, impact and benefits of emotional skills for leaders. The coach also guided the leaders in how and when to practise the emotional skills.

- Ongoing feedback - Feedback was essential during the coaching process to determine whether the leaders were heading in the right direction. The coach gave ongoing feedback to encourage leaders. Such feedback can be highly reinforcing (Cherniss et al. 1998).

- Use of cognitive behavioural techniques -The coach deepened the leaders' understanding of the connection between thoughts and behaviour. The coach assisted the leaders to explore the cognitive patterns underlying the leaders' observable behaviours. The coach encouraged the leaders to classify, assess and alter their self-limiting thoughts, beliefs and toxic emotions to develop more useful behaviours and to grow more skilful at emotional management (Neenan 2010).

- Use of homework - The leaders participated in a number of homework assignments that allowed them to observe, practise and learn about numerous El skills (Leskiw \& Singh 2007).

- Observation by the shadow coach - The coach shadowed the leaders in selected team meetings, discussions, meetings for conflict resolution or management discussions (Turner \& Goodrich 2010). By observing the same incidents, a platform was offered to the coach and the leaders for more significant dialogue and reflection on how the leaders applied the El skills. The coach shared observations on how effectively they applied and demonstrated El skills in these selected sessions.

- Examine and investigate patterns and their meaning - The coach sought to open up new insights for the leaders by bringing hidden aspects into conscious awareness and by using behavioural patterns to reveal thoughts and beliefs. The coach used patterns in the leaders' behaviour at work and their childhood to reveal their unconscious beliefs and thoughts (Passmore 2010).

- Journaling - The leaders were encouraged to reflect in their journals on their feelings, thinking and realisations during the coaching session. They were also invited to capture their learnings and challenges during the period while practising their homework. In addition, participants reflected regularly in a journal on their own realisations and growth opportunities (Turner \& Goodrich 2010).

Design principles of the transfer phase:

- Encouraged the application of skills in the work environmentThe coach required the leaders to use the new behaviours regularly and consistently over a period of a couple of months in their work environment and at home.

- Built-in support - The supervisors of the leaders were involved in the coaching journey so that they could truly grasp and support the leaders in understanding how their actions are influenced by and affect the whole organisational system. The coach provided the supervisors with information about the progress of the leaders.

Design principles of the evaluation phase:

- Conduct evaluation - With the aim of evaluating the impact of coaching on the El of the leaders, a second round of BarOn EQ-i assessments was conducted and interviews were held with the supervisors of the leaders. Based on the feedback, the coach encouraged the leaders to reward successful implementation of skills and to focus on areas which still required development (Cherniss et al. 1998; Green 2002). 